\title{
ВЛИЯНИЕ ДЕЯТЕЛЬНОСТИ ЖЕЛЕЗНОДОРОЖНОГО ТРАНСПОРТА НА ОКРУЖАЮЩУЮ СРЕДУ КАЛУЖСКОЙ ОБЛАСТИ. ПУТИ РЕШЕНИЯ ЭКОЛОГИЧЕСКИХ ПРОБЛЕМ
}

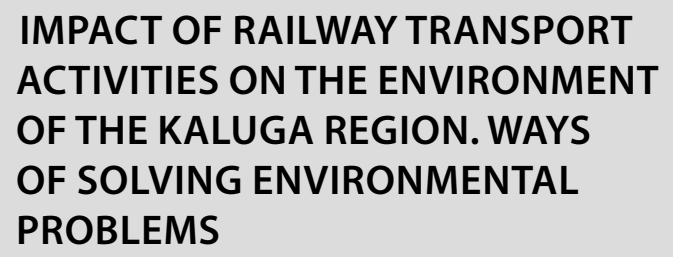

IMPACT OF RAILWAY TRANSPORT

ACTIVITIES ON THE ENVIRONMENT

OF THE KALUGA REGION. WAYS

OF SOLVING ENVIRONMENTAL PROBLEMS

A. Soskov

Summary. The railway transport of the Kaluga region is a technically complex transport complex, dispersed practically throughout its territory. In modern conditions, the study of the issues of the interaction of railway transport as the most important component of the transport complex with the environment acquires special relevance. The content of environmental protection activities in railway transport is a significant reduction and elimination of negative impact on the environment, conservation and rational use of natural resources.

Keywords: ecology, environment, railway transport, pollution, hazardous substances, 0JSC "Russian Railways".
$\mathbf{K}$ алужская область сегодня является лидером экономического развития. Несомненно, существует устойчивая связь между ростом экономики и развитием транспортной системы, особенно это касается железнодорожного транспорта, занимающего первое место среди других видов транспорта по объему грузовых перевозок. Поэтому проблема экологически сбалансированного устойчивого развития транспортных услуг является одной из актуальных [1, 2].

Железные дороги является базовой отраслью экономики и представляют собой важный, стержневой элемент транспортной системы. Железнодорожный транспорт Калужской области - технически сложный транспортный комплекс, рассредоточенной практически по всей ее территории. Железные дороги обеспечивают внутренние и внешние транспортно-экономические связи области и потребности населения в перевозках. Деятельность железнодорожного транспорта как части единой транспортной системы Калужской области, способствует функционированию всех отраслей общественного производства, социальному и экономическому развитию.

\author{
Сосков Александр Викторович \\ Аспирант, Калужский государственный \\ университет им. К.Э. Циолковского \\ Alekcandr-angel@mail.ru
}

Аннотация. Железнодорожный транспорт Калужской области - технически сложный транспортный комплекс, рассредоточенной практически по всей ее территории. В современных условиях особую актуальность приобретает исследование вопросов взаимодействия железнодорожного транспорта как важнейшей составляющей транспортного комплекса с окружающей средой. Содержанием природоохранной деятельности на железнодорожном транспорте является существенное снижение и ликвидация негативного влияния на окружающую среду, сохранение и рациональное использование природных ресурсов.

Ключевые слова: экология окружающая среда, железнодорожный транспорт, загрязнение, вредные вещества, ОАО «РЖД».

В современных условиях особую актуальность приобретает исследование вопросов взаимодействия железнодорожного транспорта как важнейшей составляющей транспортного комплекса с окружающей средой. Экологические проблемы возникают в результате взаимодействия природы и человека, при котором антропогенная нагрузка на территорию превышает экологические возможности этой территории, обусловленные главным образом ее природно-ресурсным потенциалом и общей устойчивостью природных ландшафтов [3].

Железнодорожный транспорт существенно влияет на прилегающие экосистемы, что проявляется в загрязнении воздушной, водной сред и почв при создании и эксплуатации железных дорог. Таким образом, негативное влияние железнодорожного транспорта на окружающую среду осуществляется за счет выброса вредных веществ, как от подвижного состава, так и от многочисленных производственных и подсобных предприятий, обслуживающих перевозочный процесс. При этом происходит существенное загрязнение атмосферного воздуха, воды и почвы тяжелыми металлами и их соединениями, углекислым газом, различной по химическому 
составу пылью от перевозки сыпучих грузов, видоизменение ландшафтов, деградация фитоценозов, изъятие ресурсов сельскохозяйственных земель, нарушения гидрологических условий, создание условий для развития эрозии, потеря плодородия почвы, засорение территорий, слив загрязненных вод и т.д. [4-6].

Наряду с этим происходит распространение и накопление вредных веществ на прилегающих полях и земельных угодьях, что выступает не менее вредным фактором влияния, как на окружающую среду, так и на жизнь и здоровье населения. Поскольку тяжелые металлы и их соединения обладают способностью накапливаться в сельскохозяйственных культурах, то потребление их человеком ставит под угрозу его жизнедеятельность [7].

Загрязнение воздушного бассейна выбросами вредных веществ является одной из важнейших экологических проблем на предприятиях железнодорожного транспорта. Ежегодно в атмосферу поступает значительное количество различных веществ, каждая из которых в определенной степени является опасной для живых организмов, сооружений, зданий, памятников культуры и т.д. Атмосфера загрязняется продуктами сгорания топлива, углеводородами, соединениями тяжелых металлов, аэрозолями кислот, щелочей, красок и т.д.

Значительная часть выбросов образуется за счет сжигания топлива при эксплуатации дизельного магистрального и маневрового подвижного состава, рефрижераторных поездов; на долю стационарных источников приходится 10-15\% валового объема выбросов [8].

Наиболее опасными с экологической точки зрения объектами железнодорожного транспорта являются промывочно-пропарочные пункты для наливного подвижного состава, пункты дезинфекции вагонов для перевозки животных и биологически опасных веществ, шпалопропиточные и щебеночные заводы, локомотивные и вагонные депо, подвижной состав, перевозящий нефтепродукты и взрывчатые вещества, пункты отстоя подвижного состава и др. [9].

Сточные воды железнодорожного транспорта образуются в результате эксплуатации различных технических средств, производственной деятельности локомотивных и вагонных депо, ремонтных заводов, промывочно-пропарочных и других предприятий. Количество сточных вод в среднем составляет: для локомотивных депо - 100-1000 м³/сутки; для вагонных депо 50-500 м³/сутки; для промывочно-пропарочных станций 500-2000 м³/сутки. Часть объема этих сточных вод является условно чистой, остальная масса загрязнена отходами производства $[10,11]$.
Основные виды загрязняющих примесей на указанных объектах такие: нефтепродукты - 200800 мг/л, механические примеси - 600-1400 мг/л, кислоты, щелочи, хлориды, сульфаты. В сточных водах промывочно-пропарочных станций, где проводится обработка цистерн после перевозки химических грузов, содержатся, кроме того, различные химикаты (более 130 компонентов), в том числе и ядовитые (масло креозота, фенолы, аммиак, хлористый цинк и т.д.), а в сточных водах от обработки цистерн из-под этилированного бензина - чрезвычайно опасный тетраэтил свинец - 0,01-0,03 мг/л. Наиболее загрязнены моющие растворы и обмывочные воды от моечных машин различного назначения: в них содержится 2000-20000 мг/л нефтепродуктов, В 10000 мг/л взвешенных веществ, щелочность их составляет 60750 мг-экв/л [12].

Тенденция к наращиванию производства в Калужской области, наблюдаемая в последнее время, дальнейшее поглощение современным техногенным обществом окружающей природной среды, ее постоянное загрязнение, а также необходимость экологически чистого будущего требуют немедленного решения назревших эколого-экономических проблем, активизации природоохранной деятельности.

Перевозка грузов и пассажиров предприятиями железнодорожного транспорта уже давно признана наиболее экологичной по сравнению с другими видами транспорта. Ведущие железнодорожные компании во всем мире стремятся совершенствовать свою деятельность в этом направлении и ставят перед собой еще более амбициозные цели.

Железнодорожный транспорт остро нуждается во внедрении инновационных технологий, позволяющих повысить экологическую безопасность, качество и надежность его эксплуатации, безопасность движения. Современная железнодорожная инфраструктура - это не только высокоскоростные линии, это, прежде всего, безопасность движения, прочность и надежность железнодорожного полотна, низкие затраты на его содержание, а также ограничение неблагоприятного воздействия на окружающую среду [13].

Железные дороги мира пытаются обеспечить экологическую устойчивость различными путями, среди которых применение пригодных к утилизации сырьевых материалов, использование «зеленых» методов строительства зданий и сооружений, снижение объемов потребления энергоносителей и воды, внедрение локомотивов с меньшим загрязнением атмосферы, ограничение шума и вибраций, вызванных движением поездов [15-17]. 
Всероссийский научно-исследовательский институт железнодорожного транспорта совместно с РКК «Энергия», начали разработку проекта энергетической установки на топливных элементах предназначенной для электропитания специализированной путевой техники в туннелях. Целью создания установки является освоение на железнодорожном транспорте принципиально новых энергетических установок, работающих на водороде и обеспечивают ряд технико-экономических преимуществ перед существующими энергоустановками, в том числе высокую экологичность [18].

Грузовой асинхронный электровоз $2 Э С 10$ («Гранит») - современная высокопроизводительная машина, которая при стандартных весовых параметрах способна водить поезда весом до 9-10 тыс. тонн, что примерно на 40-50\% больше, чем позволяют электровозы серии ВЛ. Кроме того, в несколько раз будут снижены затраты на обслуживание локомотива в течение его жизненного цикла. Экологичность от выбора электротяги очевидна [19].

ОАО «РЖД» непрерывно разрабатывает стратегии повышения эффективности применения всех видов ресурсов и уменьшения антропогенного воздействия на окружающую среду. Система экологического мониторинга ОАО «РЖД» позволяет: контролировать выбросы и сбросы; получать аналитическую информацию о составе и свойствах загрязнений; собирать и передавать полученную информацию в базу данных для принятия управленческих решений.

В 2018 г расходы ОАО «РЖД» на природоохранные мероприятия превысили 8,5 млрд. руб., что привело к сокращению выбросов вредных веществ в атмосферу на 4,3\%, уменьшению сбросов загрязненных сточных вод на 11\%, ликвидации 12 объектов накопленного экологического ущерба [20].

Эффективное экологическое корпоративное управление ОАО «РЖД» позволяет не только следовать национальным и мировым экологическим стандартам, но и повышает конкурентоспособность компании на рынке грузовых и пассажирских перевозок, формируя имидж экологически ответственной компании [21].

Главной целью РЖД в сфере экологии выступает забота об экологической безопасности и здоровье людей. Для ее достижения до 2025 планируется:

- на 18\% снизить выбросы загрязняющих веществ от стационарных источников;

- на 4,5\% снизить удельный уровень выбросов парниковых газов;

- на 20\% снизить использование водных ресурсов;

- на 18\% снизить сброс загрязненных сточных вод;
- 2,4\% увеличить долю обезвреживания и вовлечения во вторичный оборот отходов производства и потребления.

Однако, не смотря на применяемые меры борьбы с загрязнением воздушного бассейна, проблема остается острой и требует дальнейших усилий для разрешения $[20,21]$.

Особый акцент необходимо сделать на полезном эффекте использования искусственных лесных насаждений и естественных лесов, расположенных на полосах земельного отвода путей. В частности, защитные лесные насаждения в условиях работы железнодорожного транспорта защищают земляное полотно и гражданские сооружения от негативного воздействия водных потоков, закрепляют почвы, прикрывают линии связи, автоблокировки, централизации и сигнализации от воздействия ветра и интенсивного образования льда, являются надежным средством защиты железнодорожных путей от снежных и песчаных заносов, оползней и селевых потоков, снижают сопротивление ветровых потоков движения поездов.

Следует отметить, что 1 га таких защитных насаждений снижает общую загрязненность воздуха на 10-35\%, также обеспечивает снижение температуры и влажности воздуха в прилегающей к железнодорожному полотну зоне на 10-15\%; полоса древесно-кустарниковых насаждений шириной 25-30 м снижает уровень концентрации углекислого газа на 70\%, поглощает 75-80 кг фтора, 200 кг сернистого газа, 30-70 т пыли [3]. При этом лесозащитные полосы также защищают окружающие территории от негативного шумового эффекта, или акустического загрязнения.

Кроме того следует подчеркнуть, что лесные насаждения являются дешевым, надежным и долговременным биологическим средством защиты железнодорожного полотна от негативного воздействия природных явлений.

\section{Зак^ючение}

В современных условиях проблема рационального использования природных ресурсов и обеспечения экологической безопасности населения является необходимым условием устойчивого экономического и социального развития Калужской области.

Наряду с отраслями, которые традиционно нарушают экологическое равновесие, значительное влияние на окружающую природную среду оказывают различные виды транспорта, в том числе предприятия железнодорожного транспорта. Хотя среди всех видов транспорта 
железнодорожный транспорт остается наиболее экологичным, однако, он все-таки оказывает отрицательное влияние на окружающую среду, что обусловлено значительным потреблением воды, сбросами сточных вод, загрязнением атмосферного воздуха, образованием отходов, загрязнением почв, шумовым, вибрационным и электромагнитным излучением, ионизирующим влиянием, аварийными загрязнениями при перевозке опасных грузов и т.д.

С экологической точки зрения, устойчивое развитие предприятий железнодорожного транспорта должно обеспечивать максимальное уменьшение нагрузки на окружающую среду и поддержание целостности биологических и физических природных систем.

Функционирование и развитие транспорта, как и любого элемента техносферы, должно основываться на следующих принципах: проведение количественной и качественной оценки состояния экологических систем, природных комплексов и природных ресурсов; нормирование уровня антропогенных воздействий от различных видов деятельности, в том числе и объектов транспорта на окружающую среду; ограничения воздействия на природную среду с помощью различных методов и средств очистки атмосферных выбросов, сточных вод, отходов производства, физического воздействия; создание экологически чистых производств, технологий, подвижного состава, оборудования и транспортных систем; непрерывный контроль за состоянием окружающей среды методами экологической профилактики отраслей и объектов транспорта; использование экономических методов в управлении охраной окружающей среды и рационального природопользования; неизбежность наступления ответственности за нарушение правил, норм по охране окружающей среды.

Содержанием природоохранной деятельности на железнодорожном транспорте является существенное снижение и ликвидация негативного влияния хозяйственной деятельности объектов железнодорожного транспорта на окружающую среду, сохранение и рациональное использование природных ресурсов.

\section{ЛИТЕРАТУРА}

1. Чаусов Н.Ю., Чаусова Л. А., Горбатов А. В. Состояние природной среды Калужской области как фактор устойчивого развития региона // Региональная экономика и управление: Электронный научный журнал. — 2018. — № 4 (56). [Электронный ресурс.] — Режим доступа: https://www. printfriendly.com/p/g/ b7R2nc

2. Якунина М.В., Крутиков В. К., Посыпанова О.С. Экономическая безопасность региона: Учеб.-метод. пособие. - Калуга: КГУ имени К. Э. Циолковского, 2015.

3. К Калачева 0.А., Прицепова С. А. Проблемы воздействия подвижного состава железнодорожного комплекса на окружающую среду // Естественные и технические науки. — 2012.— № 6 (62). - С. 129-136.

4. Чернуха А. Д. Эколого-правовые требования при вводе в эксплуатации. Объектов железнодорожного транспорта // Экономика Ж. Д.—2014.— № 10.— C. 81-92.

5. Сидоров Ю.П. Практическая экология на железнодорожном транспорте: учебное пособие.— М.: ФГБоУ «Учебно-методический центр по образованию на железнодорожном транспорте», 2013.- 227 с.

6. Панова Н. С. Влияние железнодорожного транспорта на экологию // Научно-технический вестник Поволжья. — 2010.— № 1.— C. 139-144.

7. Сейпышева Д. Р. Влияние железнодорожного транспорта на окружающую среду // Экономика и менеджмент инновационных технологий. — 2019. — № 9 (96).- - С. 1.

8. Водясов П. И. Экологические аспекты железнодорожного транспорта // Проблемы современной науки. 2013. № 7-3. С. 46-52.

9. Казанцев, М. И. Железнодорожный транспорт — как источник загрязнения почв тяжелыми металлами / М. И. Казанцев // Самарский научный вестник. 一 2015.— № 2 (11).

10. Сидоров Ю. П. Практическая экология на железнодорожном транспорте. - М.: ФГБоу «Учебно-методический центр по образованию на железнодорожном транспорте», 2015.- - С. 228.

11. Капцов, В. А. Экологические проблемы железнодорожного транспорта на современном этапе / В. А. Капцов // Гигиена и санитария.— 1999.— № 2.— C. 44-46.

12. Васюкевич Е. Б. Ресурсосберегающие технологии на железнодорожном транспорте // Путь и путевое хозяйство.— 2011.— № 1.— C. 8-13.

13. Калачева 0.А., Прицепова С. А. Экологическая безопасность на железнодорожном транспорте. // В сб. «Авиакосмические технологии (АКТ-2015).2015.- - C. 305-308.

14. Малов Н.Н., Коробов Ю. И. Охрана окружающей среды на железнодорожном транспорте. — М.: Транспорт, 2004. — С. 238.

15. Проскурякова Е. А. Развитие зеленой экономики на железнодорожном транспорте // Природопользование и устойчивое развитие регионов России: сборник статей II Международной научно-практической конференции. - Пенза: РИО ПГАУ, 2019. — C. 137-140

16. Лапицкий, В. Н. Экологические аспекты железнодорожного транспорта / В. Н. Лапицкий. — Омск, 2013

17. Клочкова Е. А. Промышленная, пожарная и экологическая безопасность на железнодорожном транспорте.— М.: УмЦ ЖДТ, 2008. — С. 456. 
18. Григорович, Д.Н. Энергетическая установка на топливных элементах для работы в железнодорожных тоннелях [Электронный ресурс] / Д. Н. Григорович._- Режим доступа: http://h2forum2008.ru/docs/pdf/abstracts/5_4_01.pdf

19. Информационный центр поддержки предпринимательства о новых промышленных технологиях и изделиях [Электронный ресурс].— Режим доступа: www/URL: http://www.74rif.ru/Sinara-Simens.html

20. Писцова Н.Ф. ОАО «РЖД» - экологоориентированная компания // Безопасность городской среды.— Омск: Омский государственный технический университет, 2018. - С. 367-371.

21. Белошапкина В. И. Устойчивое развитие компании ОАО «РЖД»: экологическая составляющая // Современные тенденции развития науки и технологий. 2017.-3-13 (24).-C. 16-20.

22. Балычев, В. Д. Роль защитных лесных насаждений Нижнего Поволжья в регулировании шума: автореф. дис. канд. с.-х. наук / В. Д. Балычев. Волгоград, 2006. - $22 \mathrm{C}$.

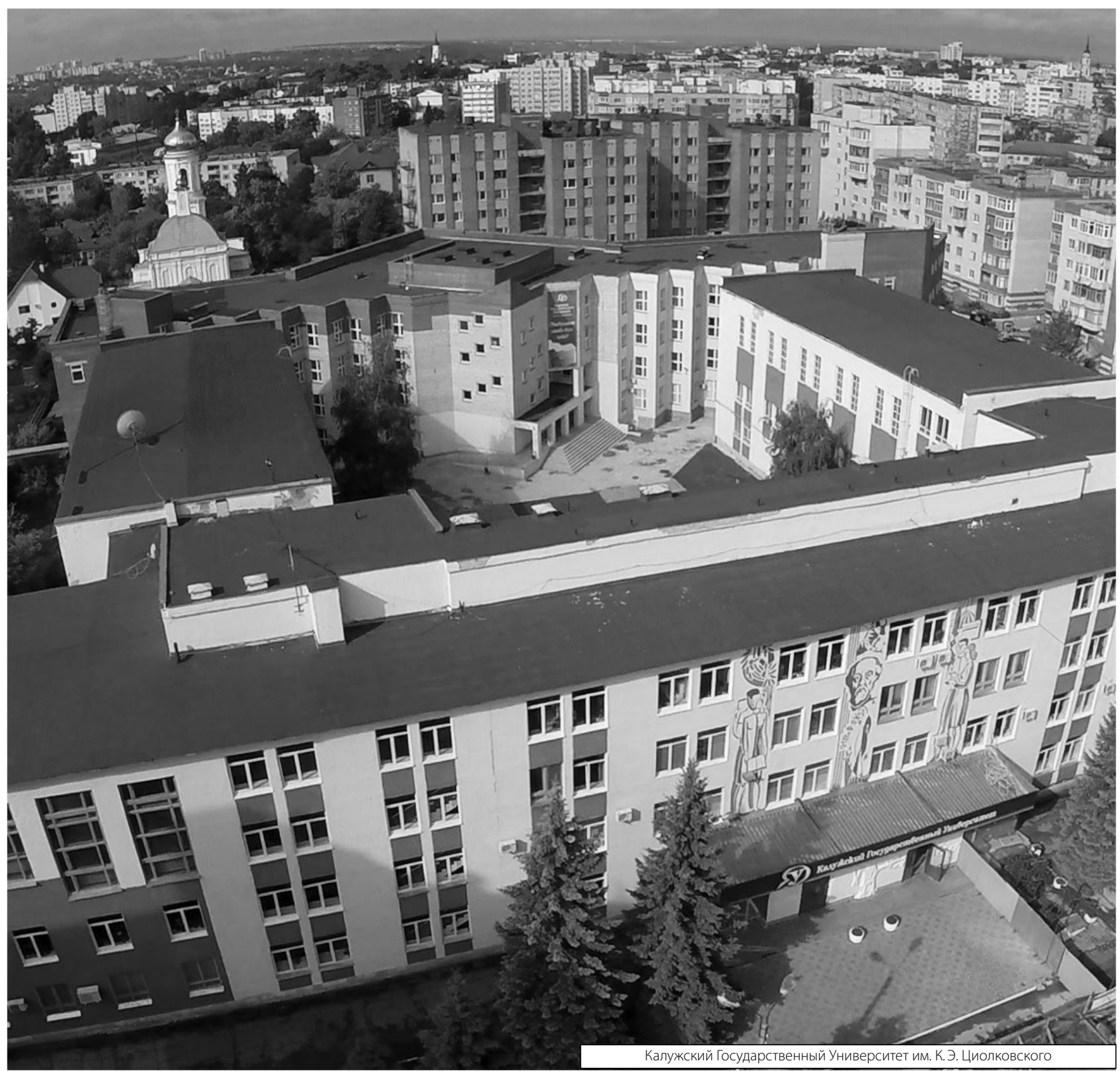

